\title{
U.S. Geological Survey Water Science Strategy
}

Water is one of our Nation's most essential natural resources and observing and understanding the water cycle, predicting changes to water, and delivering scientific information to decisionmakers is essential to water's sound management. This strategy for water science is guided by those four principles. Integrated observations of the entire water cycle are the cornerstone for water-availability science in terms of quantity and quality. Understanding the water cycle is essential to resource decisionmaking. The science we produce is applied to societal relevance by predicting changes to water availability in response to events such as sea-level rise and climate and land-use change, and informing society during water conflicts and emergencies such as floods, droughts, and water-quality degradation. To sustain the resource and contribute to safety in society, water data and science must be delivered to the public and other scientists. These guiding principles are reflected throughout this strategy and the development of its goals.

\section{Societal Issues and Water Science}

Water is essential to life on our planet and is the most widely used natural resource. Our own species cannot go more than 36 hours without water before our lives are endangered. Water is essential to every biological function of life. Water provides energy, food, habitat, hygiene, recreation, transportation, waste assimilation, and more.

This fact sheet describes the Water Science Strategy, presented in detail in Circular 1383-G, "U.S. Geological Survey Water Science Strategy-Observing, Understanding, Predicting, and Delivering Water Science to the Nation." Circular 1383-G is electronically available at http://pubs.usgs.gov/ circ/1383g/. The foundation for this science strategy is based on the fundamental importance (or value) of water availability in its broadest sense. Water availability, as defined here, encompasses aspects of water supplies (quantity and quality) and water needs. Water supplies are governed by a complex system of natural and human-induced processes, ranging in scope from local to global. Many of the processes affecting water supplies have changed in the past, and will continue to change in the future, on various time scales. Water needs are diverse, and they are increasingly in conflict. Water is a critical commodity for human consumption, agriculture, energy, and industry. Water is a fundamental requirement for ecosystem health, biodiversity, and resilience, and

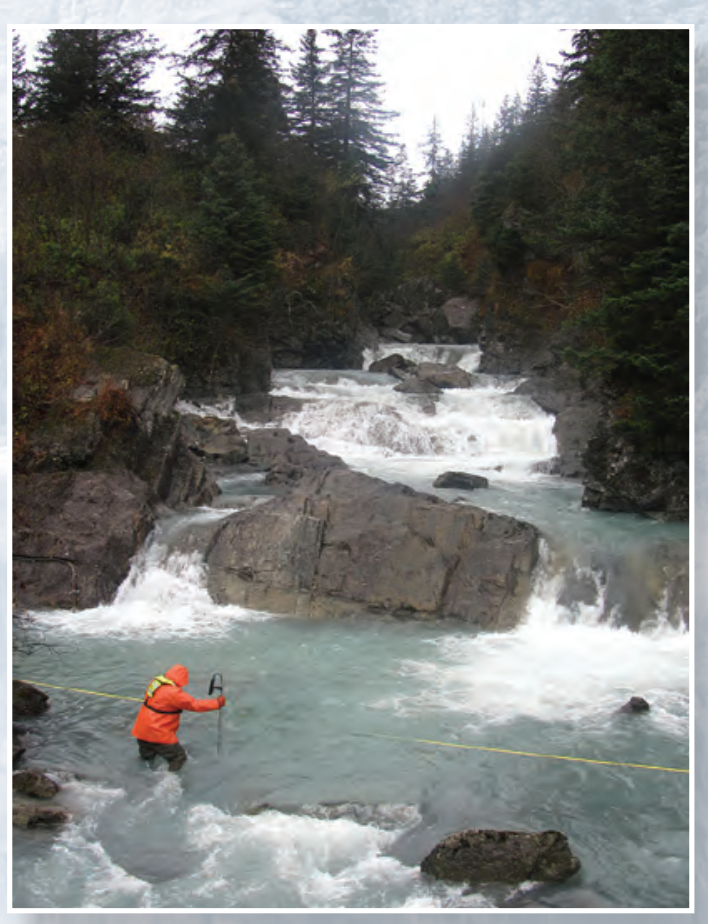
it has important recreational and aesthetic values. In many areas of the world, one or more of these aspects of water availability are under stress. Yet, the diversity of values associated with
Water availability is defined as the spatial and temporal distribution of water quantity and quality, as related to human and ecosystem needs, as affected by human and natural influences.

water availability makes it difficult to assess, predict, and manage water resources effectively. Improvements are needed in the characterization and understanding of water quantity and water quality if we are to maintain our society and quality of life.

\section{The USGS Water Science Strategy}

The U.S. Geological Survey (USGS) is a Federal science agency that provides a broad range of natural science information as the basis for sound management and policy decisions. In 2013, USGS published a Water Science Strategy, Circular 1383-G, "U.S. Geological Survey Water Science Strategy - Observing, Understanding, Predicting, and Delivering Water Science to the Nation," one of seven science strategies that span the breadth of USGS science. That strategy summarizes water science priorities that USGS is best suited to address, and will serve as a strategic framework for USGS water science goals, actions, and outcomes for the next decade. Implementation of this strategy will aid the coordination of USGS water science activities with those of other Federal agencies and provide a focal point for disseminating information to stakeholders.

Vision.-The USGS will provide unbiased knowledge of the Nation's water resources to support human well-being, healthy ecosystems, economic prosperity, and anticipate and help resolve impending water-resource conflicts and emergencies.

Mission.-The mission of USGS in

water science is to serve society through water-resource monitoring, assessment, modeling, and research to provide tools that managers and policymakers can use to preserve the quality and 
quantity of the Nation's water resource; balance water quantity and quality in relation to potential conflicting uses; understand, predict, and mitigate water-related hazards such as floods, droughts, and contamination events; and quantify the vulnerability of human populations and ecosystems to water shortages, surpluses, and degradation of water quality. USGS will provide science to achieve the following societal goals.

Goal 1-Provide society the information it needs regarding the amount and quality of water in all components of the water cycle at high temporal and spatial resolution, nationwide.

Goal 2-Advance understanding of processes that determine water availability.

Goal 3-Predict changes in the quantity and quality of water resources in response to changing climate, population, landuse, and management scenarios.

Goal 4-Anticipate and respond to water-related emergencies and conflicts.

Goal 5-Deliver timely hydrologic data, analyses, and decision-support tools seamlessly across the Nation to support water-resource decisions.

A distinct highlight of Circular 1383-G is the water cycle diagram presented on pages 20-21. This diagram embodies the complex issues that must be measured, understood, and interpreted to meet the Nation's water availability challenges.

\section{USGS Water Science Priority Actions}

- Improve integrated science planning for water;

- Expand and enhance water-resource monitoring networks;

- Characterize the water cycle through development of stateof-the-art 3-D/4-D hydrogeologic framework models at multiple scales;

- Clarify the linkage between human water use (engineered hydrology) and the water cycle (natural hydrology);

- Advance ecological flow science;

- Provide flood-inundation science and information;

- Develop rapid deployment teams for water-related emergencies;
- Conduct integrated watershed assessment, research, and modeling; and

- Deliver water data and analyses to the Nation.

\section{Intended Outcome}

The Water Science Strategy serves as a guiding document for USGS leadership in science planning and execution and will be used as a basis for budget initiatives and national and regional guidance. Through observing components of the water cycle, we can better quantify the water resource in terms of abundance and quality. Understanding the water cycle leads to development of better tools for assessing all aspects of the water resource, from water availability, to flooding, to degradation of surface waters and groundwater. Predicting modifications of the water cycle from factors such as human effects on watersheds and climate variability is important for decisionmaking to ensure the sustainability and resilience of communities and ecosystems. Finally, USGS science related to observing, understanding, and predicting components of the water cycle must be delivered to managers, policymakers, and the public in understandable and relevant ways to be an effective force in managing the water resource.

Providing water data and information are and has always been a vital service to customers, stakeholders, partners, Tribal nations, academia, and the general public. Communicating the data and information in language and formats that are relevant to specific users is a challenge that our scientists and technicians have not shied away from, and many accessible data-delivery tools, methods, and approaches are available.

Translating these data into "common language" and explaining their meaning in appropriate contexts for greater understanding and application by the public serve to bring water science to the forefront of public discourse about water quality and availability. Informing the public also instills broader understanding of water as an essential resource for humans and other living species, for environmental health, and for economic prosperity, as well as a potential hazard by way of droughts, floods, icing, debris flow, and contaminant transport.

The success of this strategy also depends on deliberate interfaces between all USGS Mission Areas. Many of the actions proposed in this plan rely on, and will be most successful through, joint implementation with the other Mission Areas of the USGS. The last chapter of the science strategy presents a synthesis of the crosscutting science with the other Mission Areas. This was one of the most important efforts undertaken during the strategic planning process.

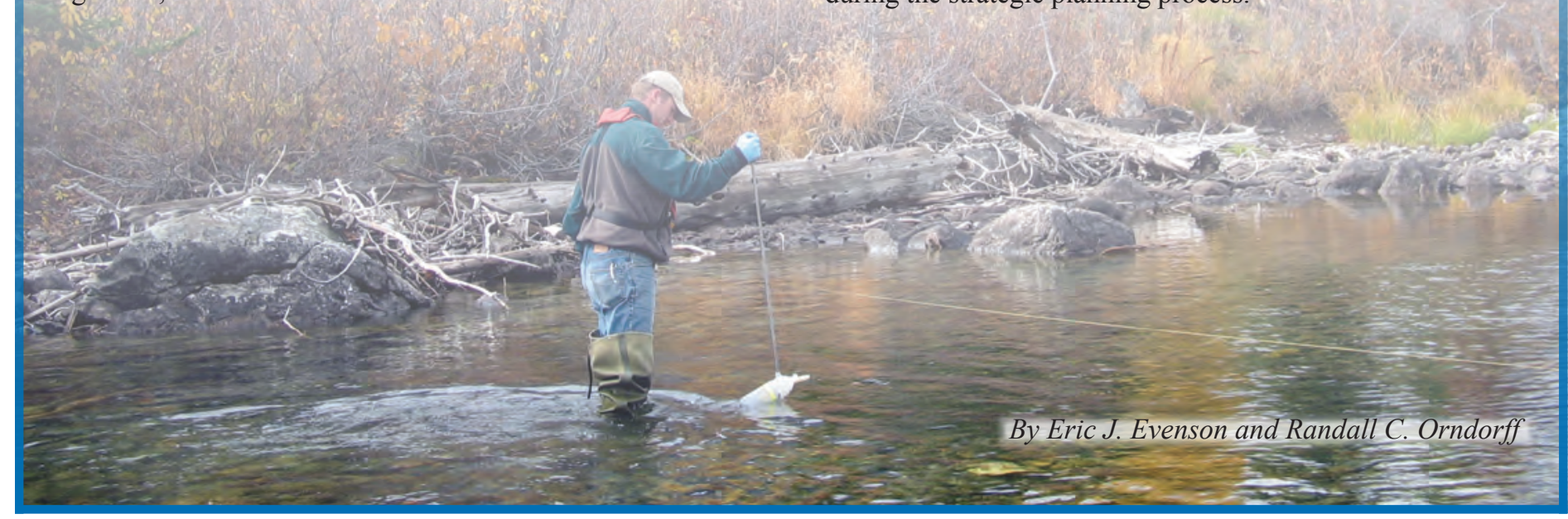

